\title{
Spectroscopic characterization of photoaccumulated radical anions: a litmus test to evaluate the efficiency of photoinduced electron transfer (PET) processes
}

\author{
Maurizio Fagnoni, Stefano Protti, Davide Ravelli and Angelo Albini ${ }^{*}$
}

\section{Full Research Paper}

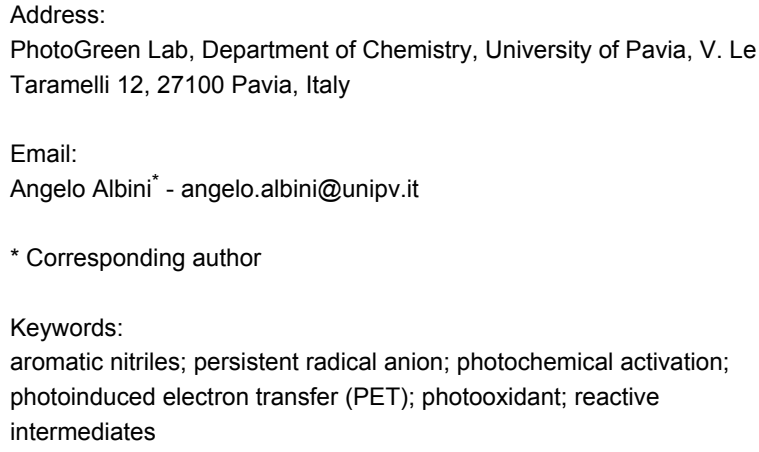

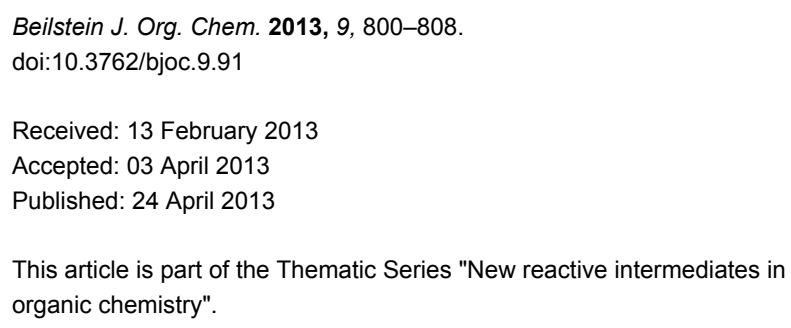

(c) 2013 Fagnoni et al; licensee Beilstein-Institut. License and terms: see end of document.

\begin{abstract}
Steady-state irradiation in neat acetonitrile of some aromatic nitriles, imides and esters $\left(10^{-5}-10^{-3} \mathrm{M}\right.$ solution) in the presence of tertiary amines allowed the accumulation of the corresponding radical anions, up to quantitative yield for polysubstituted benzenes and partially with naphthalene and anthracene derivatives. The condition for such an accumulation was that the donor radical cation underwent further evolution that precluded back electron transfer and any chemical reaction with the radical anion. In fact, no accumulation occurred with 1,4-diazabicyclo[2.2.2] octane (DABCO), for which this condition is not possible. The radical anions were produced from benzene polyesters too, but decomposition began early. Ipso substitution was one of the paths with secondary amines and the only reaction with tetrabutylstannane. The results fully support the previously proposed mechanism for electron transfer (ET) mediated photochemical alkylation of aromatic acceptors via radical ions and radical intermediates.
\end{abstract}

\section{Introduction}

Redox reactions between organic molecules have a limited scope because of the rarely matched redox potential. On the other hand, the very structure of electronically excited states makes them both easily oxidized (by donating the electron promoted to an empty orbital) and reduced (an electron is trans- ferred to the low-lying semi-occupied orbital). As a result, redox reactions are quite common in photochemistry and occur under mild conditions, avoiding the use of aggressive inorganic reagents otherwise required. Photoinduced electron transfer indeed offers an advantageous access to radical ions as well as 
the possibility to control the ensuing chemistry, in a way hardly attained through electrochemical or chemical methods [1-6]. A radical ion formed at a cathode/anode finds itself in an environment where electrons/holes are abundant. Likewise, reducing/ oxidizing chemicals must be used at a sufficiently high concentration to be active, and again the radical ions are formed in an environment where a subsequent electron-transfer step in the same direction is likely. In contrast, photoinduced electron transfer generates a radical-ion pair. Electron transfer in the reverse direction (back electron transfer, BET) is thus likely and leads again to the starting molecules [7], unless one or both of the radical ions undergoes a sufficiently fast reaction (Scheme 1). In the simplest case, one of the radical ions reacts, while the other one persists. At some point in the mechanism, BET occurs, such that the final product has undergone no net change of the oxidation level, or an equimolecular mixture of a reduced and an oxidized product is formed.

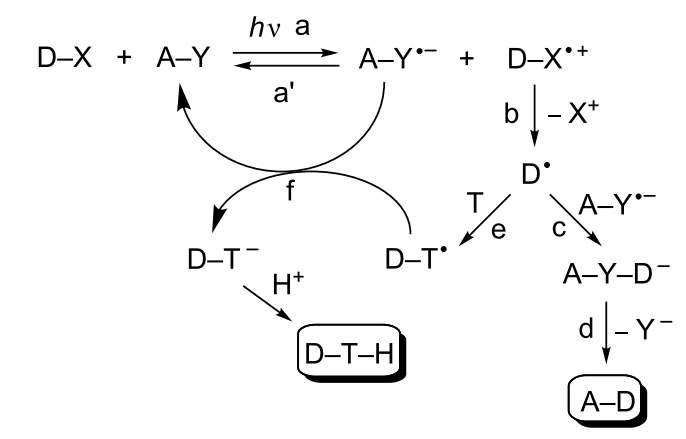

Scheme 1: Photoinduced electron transfer as an access to radical chemistry.

As an example, the largely positive reduction potential of aromatic nitriles $[5,8,9]$ and cyanophthalimides $[10]$ in the singlet excited state or of aromatic esters in the triplet state $[5,11]$ makes PET a common occurrence upon irradiation of such substrates in the presence of a variety of donors (D-X, step a). In all of the above cases, the generated radical anion $\left(\mathrm{A}-\mathrm{Y}^{\cdot-}\right)$ is a persistent species easily detected by laser flash photolysis. This approach applies to a variety of donors, including amines $[12,13]$, carboxylic acids or their derivatives [14,15], aliphatic acetals and ketals [16], ethers [17], organostannanes [18,19], organosilanes [20-22], aromatics [10,23,24], and even alkanes [25-27]. BET (path a') could ensue, thus leading to no chemical change. However, when the $\mathrm{D}-\mathrm{X}^{\bullet+}$ intermediate contained a good electrofugal group (such as a silyl, stannyl, $t$-Bu group or a hydrogen [12-27]), unimolecular fragmentation was possible and gave neutral alkyl radicals $\left(\mathrm{D}^{\bullet}\right)$ with a reasonable ( 0.1 or higher) quantum yield (Scheme 1 , step b) [5]. Addition to the aromatic radical anion and re-aromatiza- tion gave an alkylated aromatic $(\mathrm{A}-\mathrm{D}$, path $\mathrm{c} \rightarrow \mathrm{d})$, while trapping of the radical by an electron-withdrawing substituted alkene T (step e) [28,29] followed by BET from the radical anion (step $\mathrm{f}$ ) of the acceptor (that was thus recovered) led to photocatalyzed alkylation of the alkene [5,30,31]. Both processes have found some application in synthesis for the mild and selective activation of aliphatic derivatives, in particular of a $\mathrm{C}-\mathrm{H}$ bond [32].

The role of the acceptor radical anion in the above processes is thus decisive, and we report below a steady-state investigation of such species arising from aromatic compounds known to participate in photosubstitution or photocatalytic alkylation reactions. It was proposed to ascertain whether these may accumulate, as often observed in electrochemistry [33,34] and by pulse radiolysis [35], but rarely in photochemistry.

\section{Results}

The acceptors chosen for this study were nitriles, viz. 1,2,4,5tetracyanobenzene (TCB), 1,3,5-tricyanobenzene (1,3,5-TrCB), 1,2,4-tricyanobenzene (1,2,4-TrCB), 1,4-dicyanonaphthalene (DCN), 9,10-dicyanoanthracene (DCA); imides, viz. 4,5dicyanophthalimide (DCP), and its $N$-methylated derivative (DCP-Me); and esters (methyl pyromellitate, PME, and methyl mellitate, ME). Radical anions of this type have been previously observed in glasses (e.g., from the irradiation of TCB and $\alpha$-methylstyrene in isoamyl alcohol glass at $113 \mathrm{~K}$ ) [36] and in a few cases in fluid solution (from dicyanoanthracene in the presence of methoxide [37] and from 2,6,9,10-tetracyanoanthracene with amines [38]). As for the donors, these were chosen on the basis of their oxidation potential (see Table 1 and Figure 1), to allow for an overall exergonic electron transfer from the donor to the excited acceptor in all of the cases considered below [39]. The relevant redox parameters for the ground states of acceptors and donors are gathered in Figure 1, along with the reduction potentials for the excited states of the aromatics.

In the experiments, a $\mathrm{MeCN}$ solution of the acceptor in the presence of the chosen donor was deaerated by freeze-pump-thaw technique and irradiated at $313 \mathrm{~nm}$. Thus, irradiation of a $2 \times$ $10^{-4} \mathrm{M}$ solution of TCB in the presence of $\mathrm{Bu}_{4} \mathrm{Sn}\left(10^{-2} \mathrm{M}\right)$ caused a stepwise blue shift of the near UV band of TCB and a weak absorption in the visible (see Figure 2a), along with a fluorescence peak centered at $510 \mathrm{~nm}$. The conversion was complete after a few minutes, and readmitting air caused little change in the spectrum. Chromatographic examination confirmed the complete consumption of TCB and the formation of a single product, identified as 5-butyl-1,2,4-tricyanobenzene by comparison with an authentic sample [18]. The measured quantum yield of TCB consumption was 0.40 . The examination was then extended to a series of nitrogen-based 


\begin{tabular}{|c|c|c|c|c|}
\hline $\begin{array}{l}\text { acceptor/ } \\
\text { donor }\end{array}$ & $\begin{array}{c}\mathrm{A}^{\cdot-}(\text { main band }) \\
\lambda_{\max }(\mathrm{nm})\end{array}$ & $\begin{array}{c}\varepsilon\left(\times 10^{-3}\right) \\
L \mathrm{~mol}^{-1} \mathrm{~cm}^{-1}\end{array}$ & $\begin{array}{c}\mathrm{A}^{--} \text {(further maxima) } \\
\lambda_{\max }(\mathrm{nm})\end{array}$ & $\Phi_{A} \cdot-$ \\
\hline TCB/OXA & & 10.3 & & 0.15 \\
\hline TCB/TEA & & 9.6 & & 0.15 \\
\hline $\mathrm{TCB} / \mathrm{PPr}_{3} \mathrm{~N}$ & 462 & 9.8 & $436,414,375,354$ & 0.08 \\
\hline $\mathrm{TCB} / \mathrm{Et}_{2} \mathrm{NH}^{\mathrm{a}}$ & & 6.7 & & 0.15 \\
\hline TCB/MAE ${ }^{a}$ & & 2.9 & & 0.05 \\
\hline TCB (literature) $)^{b, c}$ & 462 & $\begin{array}{c}4.9, \mathrm{~b} \\
14.6-15.4^{\mathrm{c}}\end{array}$ & - & - \\
\hline 1,2,4-TrCN/OXA & 351 & 2.3 & 433,397 & - \\
\hline DCN/OXA & $\begin{array}{l}389 \\
512\end{array}$ & $\begin{array}{l}5.4 \\
1.0\end{array}$ & $621,500,481$ & - \\
\hline $\mathrm{DCN}(\text { literature })^{\mathrm{d}}$ & 512 & $3.6^{\mathrm{d}}$ & - & - \\
\hline DCA/OXA & $\begin{array}{l}705 \\
640\end{array}$ & $\begin{array}{l}0.6 \\
0.4\end{array}$ & 520 & - \\
\hline $\mathrm{DCA}$ (literature) $^{\mathrm{e}}$ & 640 & $5.6^{\mathrm{e}}$ & - & - \\
\hline $\mathrm{DCP} / \mathrm{OXA}$ & 577 & 25.6 & 536,382 & - \\
\hline DCP-Me/OXA & 578 & 26.3 & 537,390 & - \\
\hline ME/OXA ${ }^{a}$ & 527 & 0.80 & 368 & - \\
\hline $\mathrm{PME} / \mathrm{OXA}^{\mathrm{a}}$ & 533 & 1.4 & 371 & - \\
\hline
\end{tabular}

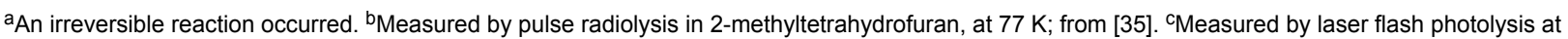
room temperature of a MeCN solution of 1,2,4-trimethylbenzene or o-xylene as donors, see [24]. dMeasured by laser flash photolysis at room temperature of a DMF solution of alkyltriphenyl borate anions as donors; from [40]. ${ }^{\mathrm{e}}$ Measured by electrolysis in DMF at room temperature; from [34].

donors. In the presence of 2,2,3-trimethyloxazolidine (OXA), a yellow color developed and a spectrum with maxima at 462 , 375 and $354 \mathrm{~nm}$ was registered (see Figure 2b) along with shoulders at 436 and $414 \mathrm{~nm}$. The final absorption was qualitatively and quantitatively close to that reported in the literature for the TCB radical anion (see Table 1). Thus, conversion was deemed to be complete, with a 0.15 quantum yield of formation of $\mathrm{TCB}^{\circ-}$. Readmitting air in this case caused the disappearance of the color and the full regeneration of the starting nitrile, as confirmed by chromatographic analysis.

Exactly the same behavior was observed by using triethylamine (TEA) as the donor. It is noteworthy from the practical point of view that with $\mathrm{OXA}$ the $\mathrm{TCB}^{\circ-}$ was formed at about the same rate also in a nitrogen- or argon-flushed solution, whereas with TEA and the other donors discussed below a more rigorous deaeration such as the freeze-pump-thaw method was required. Again similar was the behavior of triisopropylamine, which showed a somewhat lower quantum yield (0.08), however, in the formation of $\mathrm{TCB}^{\circ-}$. The use of diethylamine $\left(\mathrm{Et}_{2} \mathrm{NH}\right)$ led initially to the accumulation of the $\mathrm{TCB}^{--}$absorption up to ca. $2 / 3$ rd of the maximum value with TEA, but then a different evolution began to manifest. In this case, oxygen quenching eliminated the radical anion but left some absorption (with maxima at 390 and $290 \mathrm{~nm}$ ). With $N$-(methylamino)ethanol (MAE) a lesser amount of $\mathrm{TCB}^{--}$was formed and the new absorption at $290 \mathrm{~nm}$, as above, was apparent already during the irradiation (not shown). On the other hand, the $\mathrm{TCB}^{--}$spectrum did not develop in the presence of DABCO. In this case, TCB was only sluggishly consumed, and a new absorption band with a maximum at $380 \mathrm{~nm}$ grew, which was unaffected when air was readmitted.

The investigation was then extended to further acceptors by using TEA and OXA, which had demonstrated to be the best donors for the accumulation of the acceptors radical anions. Actually, almost superimposable results were obtained, and in the following, only the results with the latter donor are mentioned.

The irradiation of a $5 \times 10^{-4} \mathrm{M}$ solution of $1,2,4-\mathrm{TrCB}$ in the presence of OXA resulted in the development of a new absorption band, with sharp peaks at 351 and $433 \mathrm{~nm}$ and a broad shoulder around $400 \mathrm{~nm}$, fully reversed on readmitting air. The signals were attributed to the $1,2,4-\operatorname{TrCB}$ radical anion, to the best of our knowledge not previously characterized (see Figure $3 \mathrm{a}$ ), on the basis of the analogy with $\mathrm{TCB}^{\cdot-}$. This was not the case for $1,3,5-\operatorname{TrCB}$, where little if any of the radical anion $[35,41,42]$ was formed and an irreversible modification of the spectrum occurred. Indeed none of the maxima known in the literature for this radical anion $(532,342$ and $332 \mathrm{~nm})$ developed [35]. 
<smiles>N#Cc1cc(C#N)c(C#N)cc1C#N</smiles>

$\mathrm{TCB}, \mathrm{E}_{\mathrm{A} / \mathrm{A}}{ }^{--}=-0.66 \mathrm{~V}$

$\mathrm{E}_{\mathrm{A}^{*} / \mathrm{A}^{--}}=3.44 \mathrm{~V}$<smiles>N#Cc1ccc(C#N)c2ccccc12</smiles>

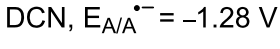

$E_{A^{*} / A^{--}}=2.17 \mathrm{~V}$<smiles></smiles>

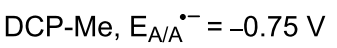

$E_{A^{*} / A^{--}}=3.11 \mathrm{~V}$<smiles>N#Cc1cc(C#N)cc(C#N)c1</smiles>

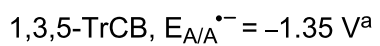

$E_{A^{*} / A^{*-}}=2.68 \mathrm{~V}$<smiles>N#Cc1c2ccccc2c(C#N)c2ccccc12</smiles>

DCA, $E_{A / A}{ }^{--}=-0.89 \mathrm{~V}$

$E_{A^{*} / A^{--}}=2.53 \mathrm{~V}$<smiles>COC(=O)c1cc(C(=O)OC)c(C(=O)OC)cc1C(C)=O</smiles>

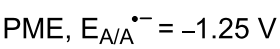

$E_{A^{*} / A^{\cdot-}}=1.73 \mathrm{~V}$<smiles>N#Cc1ccc(C#N)c(C#N)c1</smiles>

$1,2,4-\operatorname{TrCB}, \mathrm{E}_{\mathrm{A} / \mathrm{A}}{ }^{--}=-1.17 \mathrm{~V}^{\mathrm{a}}$

$E_{A^{*} / A} \cdot-3.09 \mathrm{~V}$<smiles>N#Cc1cc2c(cc1C#N)C(=O)NC2=O</smiles>

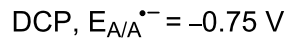

$E_{A^{*} / A^{*-}}=3.11 \mathrm{~V}$<smiles>COC(=O)c1c(C(C)=O)c(C(=O)OC)c(C(=O)OC)c(C(=O)OC)c1C(=O)OC</smiles>

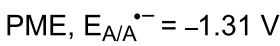

$E_{A^{*} / A^{--}}=1.95 \mathrm{~V}$
$\mathrm{Bu}_{4} \mathrm{Sn}, \mathrm{E}_{\mathrm{D}}{ }^{+} / \mathrm{D}=1.62 \mathrm{~V}$

$\mathrm{Et}_{2} \mathrm{NH}, \mathrm{E}_{\mathrm{D}}^{\cdot+\mathrm{D}}=0.78 \mathrm{Va}$

$\mathrm{HO}^{\mathrm{H}} \backslash \mathrm{MAE}, \mathrm{E}_{\mathrm{D}}^{\cdot+} / \mathrm{D}=1.16 \mathrm{~V}^{\mathrm{a}}$

$\mathrm{DABCO}, \mathrm{E}_{\mathrm{D}}^{\cdot+} / \mathrm{D}=0.69 \mathrm{~V}$
$\mathrm{iPr}_{3} \mathrm{~N}, \mathrm{E}_{\mathrm{D}}{ }^{+} / \mathrm{D}=0.70 \mathrm{~V}$

$\mathrm{Et}_{3} \mathrm{~N}(\mathrm{TEA}), \mathrm{E}_{\mathrm{D}}^{\cdot+} / \mathrm{D}=0.78 \mathrm{~V}$

$\mathrm{CH}_{\mathrm{N}}^{\mathrm{O}} \mathrm{OXA}, \mathrm{E}_{\mathrm{D}}^{\cdot+} / \mathrm{D}=1.22 \mathrm{~V}^{\mathrm{a}}$

Figure 1: Reduction potential (versus SCE) of the ground and excited state of acceptors and oxidation potential of the ground-state donors examined in this work. aValue measured in the present work (see Experimental).

a)

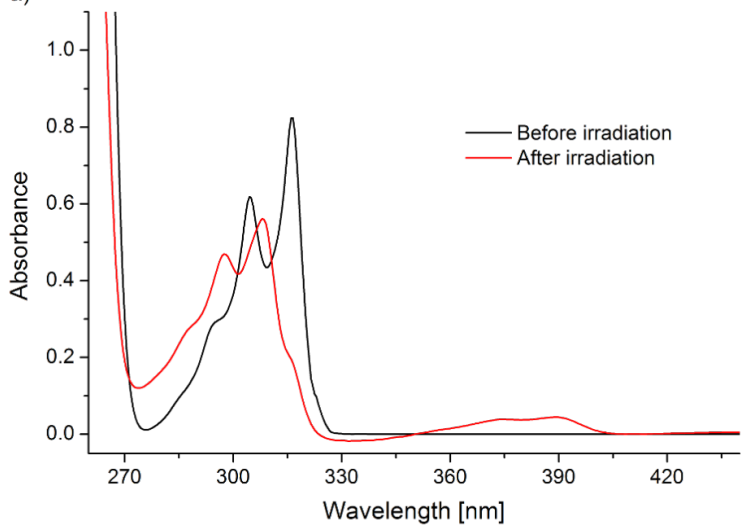

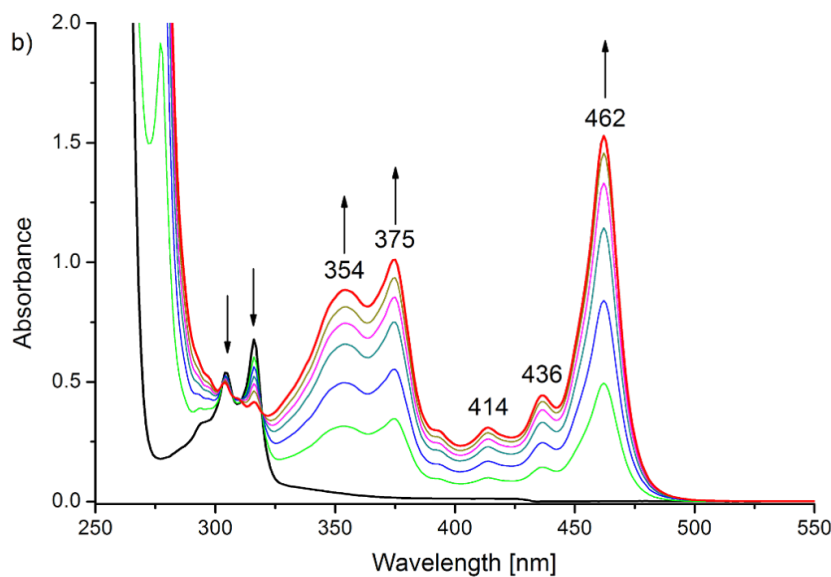

Figure 2: UV-monitoring of: (a) a $2 \times 10^{-4} \mathrm{M}$ solution of TCB in the presence of $\mathrm{Bu}_{4} \mathrm{Sn}\left(10^{-2} \mathrm{M}\right)$ and $(\mathrm{b})$ a $1.5 \times 10^{-4} \mathrm{M}$ solution of TCB in the presence of OXA $\left(5 \times 10^{-2} \mathrm{M}\right)$ in freeze-pump-thaw deoxygenated MeCN $\left(\lambda_{\mathrm{IRR}}=313 \mathrm{~nm}\right)$ from 0 (black line) to $15 \mathrm{~min}$ (red line). 

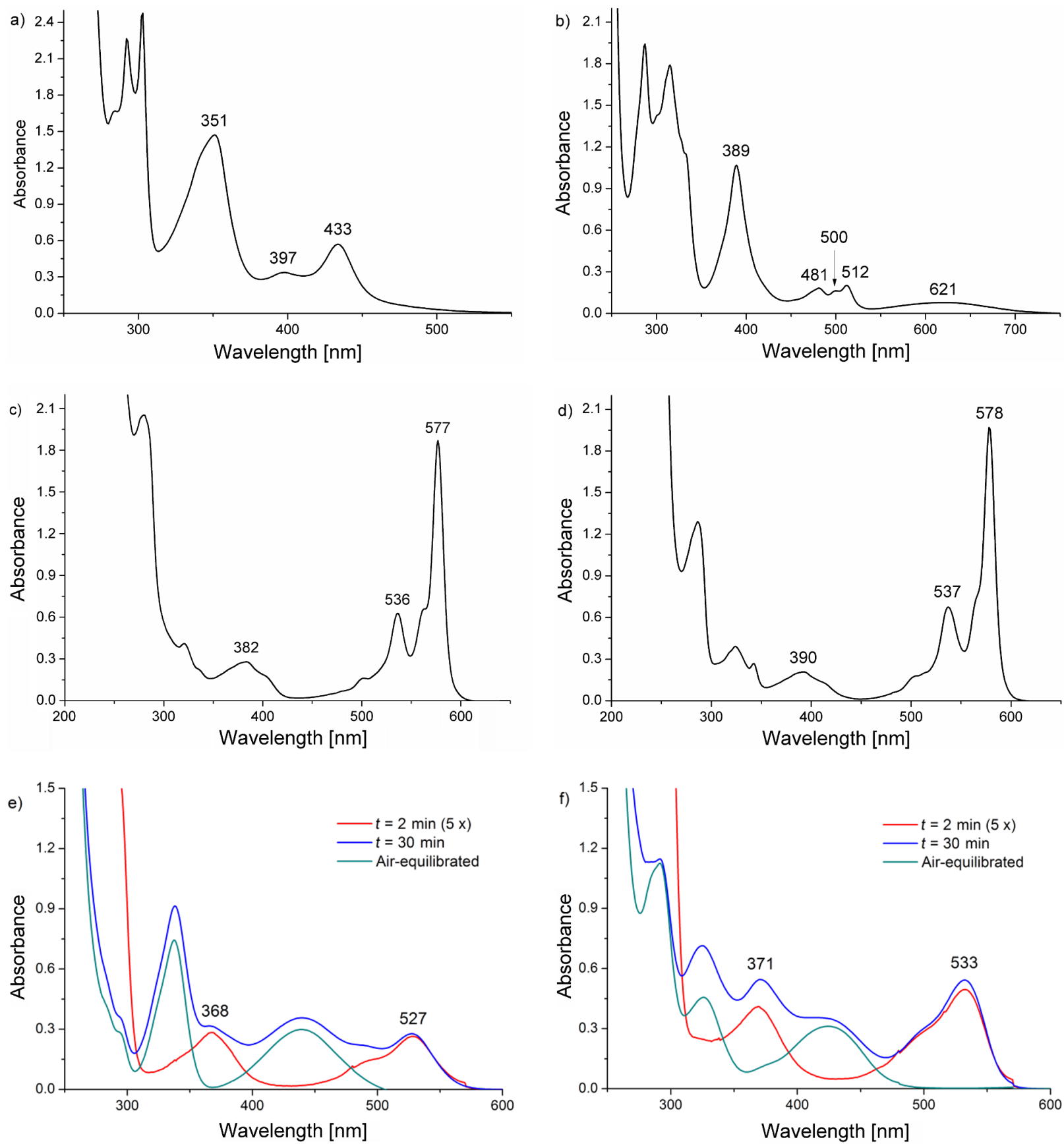

Figure 3: Absorption spectra of a freeze-pump-thaw deoxygenated MeCN solution irradiated at $313 \mathrm{~nm}$ of $(\mathrm{a}) 1,2,4-\mathrm{TrCB}\left(5 \times 10^{-4} \mathrm{M}\right)$ in the presence of OXA $\left(5.0 \times 10^{-2} \mathrm{M}\right), 20 \mathrm{~min}$ irradiation; (b) DCN $\left(2 \times 10^{-4} \mathrm{M}\right)$ in the presence of OXA $\left(5.0 \times 10^{-2} \mathrm{M}\right) \mathrm{and} \mathrm{Bu}_{4} \mathrm{NH}_{2} \mathrm{PO}_{4}\left(5 \times 10^{-3} \mathrm{M}\right), 60 \mathrm{~min}$ irradiation; (c) DCP $\left(7.5 \times 10^{-5} \mathrm{M}\right)$ and OXA $\left(5.0 \times 10^{-2} \mathrm{M}\right), 3 \mathrm{~min}$ irradiation; (d) DCP-Me $\left(7.5 \times 10^{-5} \mathrm{M}\right)$ and OXA $\left(5.0 \times 10^{-2} \mathrm{M}\right), 3 \mathrm{~min}$ irradiation; $(\mathrm{e})$ ME $\left(4 \times 10^{-4} \mathrm{M}\right)$ in the presence of OXA $\left(5.0 \times 10^{-2} \mathrm{M}\right)$ after 2 (red) and 30 (blue) min irradiation and after air equilibration of the 30 min photolyzed solution (green); (f) PME $\left(4 \times 10^{-4} \mathrm{M}\right)$ in the presence of OXA $\left(5.0 \times 10^{-2} \mathrm{M}\right)$ after 2 (red) and 30 (blue) min irradiation and after air equilibration of the 30 min photolyzed solution (green).

Analogously, in the case of DCN the corresponding radical anion [40] was not detected, while a broad, non-oxygen-sensitive band at ca. $390 \mathrm{~nm}$ was observed. On the other hand, when the same irradiation was performed after the addition of
$\mathrm{Bu}_{4} \mathrm{NH}_{2} \mathrm{PO}_{4}\left(5 \times 10^{-3} \mathrm{M}\right)$ the formation of pale green $\mathrm{DCN}^{\bullet-}$ occurred with moderate efficiency $(30 \%$ yield based on the $\varepsilon$ of $\mathrm{DCN}^{\circ-}$ reported in the literature, $3578 \mathrm{~L} \mathrm{~mol}^{-1} \mathrm{~cm}^{-1}$ at $512 \mathrm{~nm}$ [40]; see Figure 3b). As for DCA, only a tiny amount of the 
radical anion [35] was generated (data not shown). A purple color and conspicuous bands developed in the case of phthalimides DCP and DCP-Me, with sharp peaks at 577-578 and $535-536 \mathrm{~nm}$ and a broad band at ca. $400 \mathrm{~nm}$ (see Figure $3 \mathrm{c}$ and Figure $3 \mathrm{~d}$ ), reversible with air. These were attributed to the corresponding radical anions, not previously characterized, but fitting with a computational prediction of $559 \mathrm{~nm}$ for the radical anion of the unsubstituted $N$-methylphthalimide [43]. Finally, with both of the aromatic esters investigated, the bands of the corresponding pink radical anions (ME, 368 and $527 \mathrm{~nm}$ [44]; PME, 371 and $533 \mathrm{~nm}, \mathrm{Bu}_{4} \mathrm{NH}_{2} \mathrm{PO}_{4}$ added) were initially formed, but prolonged irradiation caused the formation of different absorption bands around 335 and $440 \mathrm{~nm}$ (see Figure 3e and Figure 3f). The former signals disappeared after air equilibration, while the latter persisted. Chromatographic analysis showed the formation of a strongly polar product (not identified).

\section{Discussion}

Figure 2 and Figure 3 and comparison with the literature allow us to classify the behavior of the acceptors into three groups. Polycyanobenzenes (with the exception of 1,3,5-TrCB) and cyanophthalimides form conspicuously the radical anion. Where known (as in the case of TCB), the spectrum corresponds closely to that reported (with small differences due to the different medium), and the intensity of the signals observed suggests that the conversion is almost complete. The accumulation of such species up to quantitative yield is demonstrated in neat $\mathrm{MeCN}$. This can be related to extensive localization of the charge at the electronegative atoms, which makes these radical anions nonbasic and not nucleophilic [19,23,38]. In the second group, DCN gives a much less than unitary amount (ca. 30\%) of the radical anion, and DCA barely a trace. This is reasonably related to the lower charge delocalization on the nitrogen atoms with respect to the above benzonitriles. In accordance with this idea, the DCN radical anion has been shown to accumulate to a larger degree in the presence of salts that afford a better stabilization. Finally, the esters accumulate to a certain extent (ca. $30 \%$ ), but at this level, within the time of the steady-state experiments, they begin to undergo some decomposition. These radical anions have been reported to undergo loss of the alkyl group [45], and this reasonably explains the observed irreversible decomposition. The notes above define the requirement for accumulation of radical anions: no chemical reaction (and this excludes esters) and sufficient stabilization by both aromatic substituent and medium.

On the other hand, the choice of the donor is equally decisive, because of the different reactivity of the corresponding radical cations. These may be classed again in three groups: those that undergo exclusively BET (Scheme 2, path a'), those that undergo an irreversible reaction not involving the radical anion (path $b^{\prime}$ ), and those that react with it (path c').

Thus, tertiary amines are known to undergo deprotonation from the $\alpha$-position to produce a radical that is in turn easily oxidized

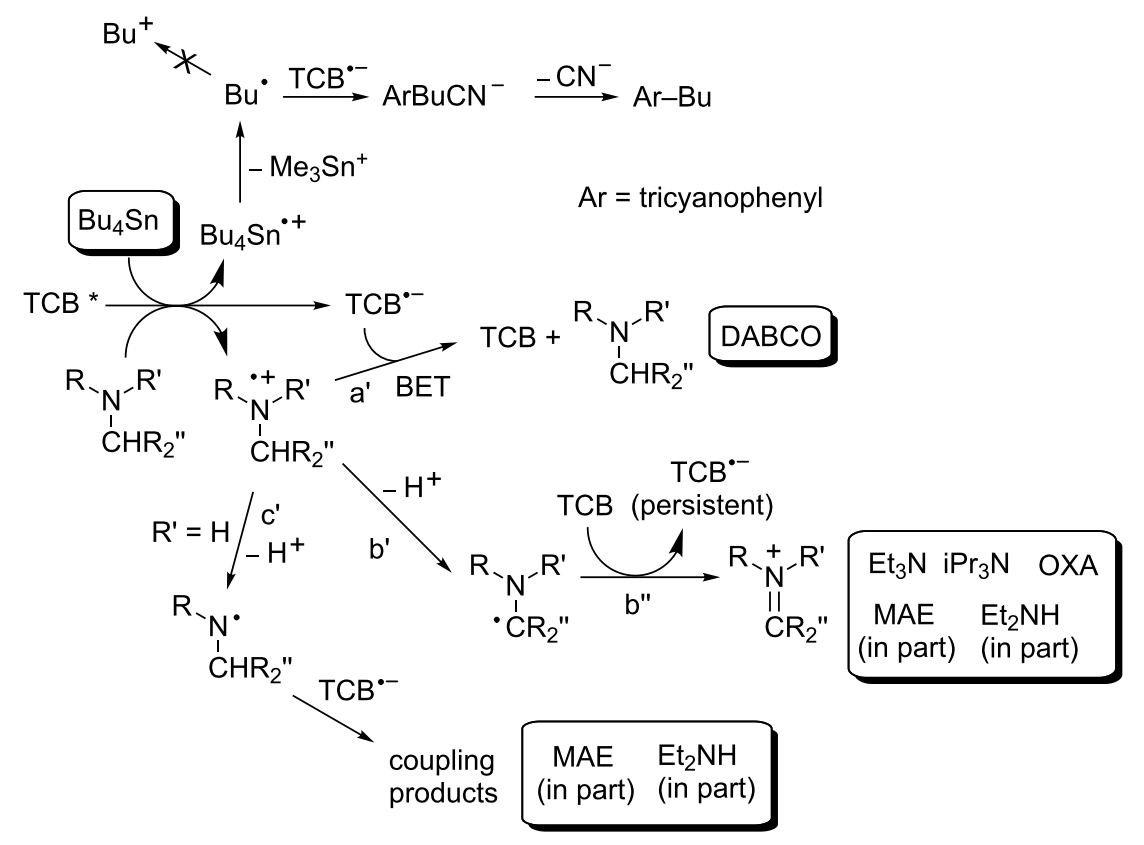


to the iminium cation. In the present examples, such radicals are oxidized by the ground-state sensitizer $(E=-1.12 \mathrm{~V}$ versus SCE for the $\alpha$-aminoradical resulting from TEA, see path $\beta$ in Figure 4 [46] and path $b$ " in Scheme 2). In this way, radical cations are destroyed, and a second equivalent of $\mathrm{TCB}^{--}$is generated and accumulated. The quantum yield is $2 k_{\mathrm{b}^{\prime}} /\left(k_{\mathrm{a}^{\prime}}+\right.$ $\left.k_{\mathrm{b}^{\prime}}\right)$, although the measured value $(0.15)$ is probably lower than the ideal value because of side processes in solution. Notice that, although TEA and OXA form $\mathrm{TCB}^{--}$at the same rate in rigorously deaerated solutions, only the latter donor allows accumulation in solutions that have been merely nitrogen flushed and capped. Separation of radical ions appears to be faster in OXA due to conformational factors, in particular the steric bulk of the methyl groups. The more efficiently formed radicals scoop away traces of oxygen still present under these conditions.

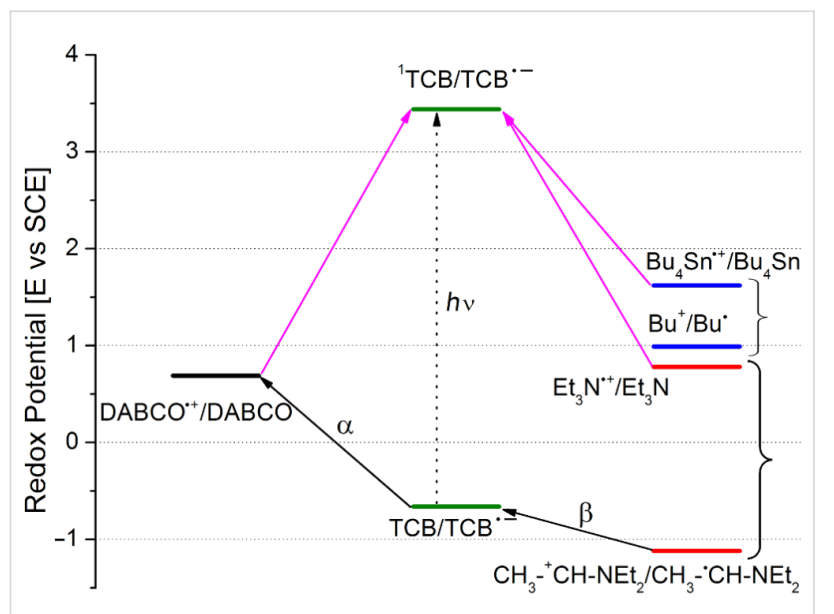

Figure 4: Thermodynamics of the redox processes discussed (solid arrows represent exergonic electron donation in the sense indicated). Thus, $\mathrm{Et}_{3} \mathrm{~N}, \mathrm{Bu}_{4} \mathrm{Sn}$ and $\mathrm{DABCO}$ all are oxidized by ${ }^{1} \mathrm{TCB}$ (ET; purple arrows). Likewise BET from $\mathrm{TCB}^{\circ-}$ is always viable and is the only possibility for DABCO (path $\alpha$ ). $\mathrm{Et}_{3} \mathrm{~N}^{\cdot+}$ cleaves and the radical generated is oxidized by TCB (path $\beta$ ), whereas this is not possible for the $\mathrm{Bu}^{*}$ radical formed by cleavage of the stannane (the potential of the $\mathrm{Bu}^{+} / \mathrm{Bu}^{*}$ couple is approximated here by that of the ethyl cation/ethyl radical couple [47]).

Likewise, in accordance with the role of amine radical cation deprotonation, is the fact that, of the two further tertiary amines, $\mathrm{iPr}_{3} \mathrm{~N}$ causes a somewhat slower accumulation (the conformation of the radical cation is known to be less favorable for deprotonation) [48-50], and DABCO (for which deprotonation is impossible [51,52]) causes no detectable formation of $\mathrm{TCB}^{\circ-}$. Indeed, previous laser flash photolysis experiments had shown that DABCO formed the TCB radical anion on the nanosecond time scale just as the other tertiary amines [53]. However, no reaction able to eliminate radical cations was viable in this case, and thus BET predominated (path a' in Scheme 2 and path $\alpha$ in Figure 4).
Irreversible decomposition of TCB takes place to a small extent with $\mathrm{DABCO}$, but it is much more conspicuous with secondary amines and the only path with the stannane. Radical cations of secondary amines are rather acidic $\left(\mathrm{p} K_{\mathrm{a}}=5.3\right.$ for $\left.\mathrm{Et}_{2} \mathrm{NH}^{\bullet+}[54]\right)$ and undergo both $\alpha-\mathrm{C}-\mathrm{H}$ and $\mathrm{N}-\mathrm{H}$ deprotonation, the latter process being also kinetically favored. Furthermore, the aminyl radical has been reported to couple with cyanoaromatics in a nonreversible process as reported by Correa et al. [55]. This justifies the formation of a stable photoproduct non-reoxidized by oxygen (path c' in Scheme 2). As for the stannane, cleavage of the radical cation to give $\mathrm{Bu}_{3} \mathrm{Sn}^{+}$and $\mathrm{Bu}^{\bullet}$ is favored. The $\mathrm{C}$-centered radical is not oxidized by $\mathrm{TCB}^{--}$(see Figure 4 ) but couples with it, resulting in efficient ipso-substitution of the nitrile ( $\Phi 0.40)$ [18]. Thus, only path b' alone leads to the accumulation of the radical anion.

\section{Conclusion}

The above experiments evidence the possibilities and the requirements for accumulating radical anions of electron-withdrawing substituted aromatics in neat organic solution. Apart from the spectroscopic interest, these data have a bearing on the mechanism of ET reactions such as those in Scheme 1 and Scheme 2. Aliphatic radical cations absorb poorly and are difficult to detect, but the conspicuous absorbance of the accompanying aromatic radical anions (the spectroscopic properties of which have been gathered in Table 1) gives most of the required information about the kinetic viability of the processes competing, offering through their bright colour a sort of litmus test for their evolution.

\section{Experimental}

The photochemical acceptors TCB, DCA, as well as the donors triethylamine $\left(\mathrm{Et}_{3} \mathrm{~N}\right)$, triisopropylamine $\left(\mathrm{iPr}_{3} \mathrm{~N}\right)$, 1,4-diazabicyclo[2.2.2] octane (DABCO), diethylamine $\left(\mathrm{Et}_{2} \mathrm{NH}\right)$ and 2-( $\mathrm{N}-$ methylamino)ethanol (MAE) were commercially available. 1,3,5-TrCB [56], 1,2,4-TrCB [56], DCN [57], DCP [10], DCPMe [10], ME [58], PME [11] and OXA [59] were obtained by known procedures. Since oxygen could interact with the photogenerated radical anions, resulting in a back oxidation [6], all of the experiments were carried out in freeze-pump-thaw deoxygenated solutions, except where otherwise noted. The examined solutions were irradiated on an optical bench equipped with a $150 \mathrm{~W}$ high-pressure mercury lamp, $\left(\lambda_{\mathrm{IRR}}=313 \mathrm{~nm}\right)$. The electrochemical properties of TCB [8,9], DCN [8,9], DCA [8,9], DCP [10], DCP-ME [10], ME [45], PME [28], Et ${ }_{3} \mathrm{~N}$ [60], ${ }_{i{ }_{3}} \mathrm{~N}$ [61], DABCO [61] and $\mathrm{Bu}_{4} \mathrm{Sn}$ [62] were available in the literature. Electrochemical measurements (cyclic voltammetry) on the other compounds $\left(\mathrm{Et}_{2} \mathrm{NH}, \mathrm{MAE}, \mathrm{OXA}, 1,3,5-\mathrm{TrCB}\right.$ and $1,2,4-\mathrm{TrCB})$ were performed on $5 \times 10^{-2} \mathrm{M}$ solutions of the analyte in a three-electrode cell (volume $10 \mathrm{~mL} ; n-\mathrm{Bu}_{4} \mathrm{NClO}_{4}$ $0.1 \mathrm{M}$ as the supporting electrolyte) with glassy carbon (dia- 
meter $2 \mathrm{~mm}$ ) as the working electrode, Pt wire as the auxiliary electrode, and $\mathrm{Ag} / \mathrm{AgCl}(3 \mathrm{M} \mathrm{NaCl})$ as the reference electrode. Scan speed was $50 \mathrm{mV} \mathrm{s}^{-1}$. The potential range investigated was $0 /+2.5 \mathrm{~V}$ for oxidation and $0 /-2.5 \mathrm{~V}$ for reduction processes. The electrochemical measurements were carried out by a BASi computer-controlled electrochemical analyzer. The potentials measured were then referred to SCE, applying the equation $E($ versus $\mathrm{SCE})=E($ versus $\mathrm{Ag} / \mathrm{AgCl} ; 3 \mathrm{M} \mathrm{NaCl})-35 \mathrm{mV}$. The redox potential of the excited state of compounds TCB $[8,9]$, DCN [8,9], DCA [8,9], DCP [10] and DCP-ME [10] were taken from the literature, whereas the redox potentials of the excited state of 1,3,5-TrCB [21], 1,2,4-TrCB [21], ME [58] and PME [28] were determined by the Rehm-Weller equation [63].

\section{Acknowledgements}

We thank Dr. Daniele Merli for the electrochemical measurements. S.P. acknowledges MIUR, Rome (FIRB-Futuro in Ricerca 2008 project RBFR08J78Q) for financial support.

\section{References}

1. Hoffmann, N. J. Photochem. Photobiol., C: Photochem. Rev. 2008, 9, 43-60. doi:10.1016/j.jphotochemrev.2008.04.002

2. Ischay, M. A.; Yoon, T. P. Eur. J. Org. Chem. 2012, 3359-3372. doi:10.1002/ejoc.201101071

3. Albini, A.; Fagnoni, M.; Mella, M. Photoinduced electron transfer: perspectives in organic synthesis. In Chemistry at the Beginning of the Third Millennium: Molecular Design, Supramolecules, Nanotechnology and Beyond, Proceedings of the German-Italian Meeting of Coimbra Group Universities, Pavia, Oct 7-10, 1999; Fabbrizzi, L.; Poggi, A., Eds.; Springer: Berlin, 2000; pp 83-101. doi:10.1007/978-3-662-04154-3_5

4. Griesbeck, A. G.; Hoffmann, N.; Warzecha, K.-D. Acc. Chem. Res. 2007, 40, 128-140. doi:10.1021/ar068148w

5. Mella, M.; Fagnoni, M.; Freccero, M.; Fasani, E.; Albini, A. Chem. Soc. Rev. 1998, 27, 81-89. doi:10.1039/A827081Z

6. Marin, M. L.; Santos-Juanes, L.; Arques, A.; Amat, A. M.; Miranda, M. A. Chem. Rev. 2012, 112, 1710-1750. doi:10.1021/cr2000543

7. Fox, M. A. Photoinduced Electron Transfer in Organic Systems: Control of Back Electron Transfer. In Advances in Photochemistry; Volman, D. H.; Hammond, G. S.; Gollnick, K., Eds.; John Wiley \& Sons, Inc.: Hoboken, NJ, USA, 1986; Vol. 13, p 237. doi:10.1002/9780470133439.ch4

8. Fox, M. A. Photoinduced Electron Transfer part A. Conceptual Basis; Chanon, M., Ed.; Elsevier: Amsterdam, 1988.

9. Schmittel, M.; Ghorai, M. K. Reactivity patterns in radical ions - A unifying picture of radical-anion and radical-cation transformations. In Electron Transfer in Chemistry; Balzani, V., Ed.; Wiley-VCH: Weinheim, Germany, 2001; pp 5-54. doi:10.1002/9783527618248.ch15

10. Freccero, M.; Fasani, E.; Albini, A. J. Org. Chem. 1998, 58 , 1740-1745. doi:10.1021/jo00059a023

11. Fagnoni, M.; Mella, M.; Albini, A. J. Phys. Org. Chem. 1997, 10, 777-780.

doi:10.1002/(SICI)1099-1395(199710)10:10<777::AID-POC940>3.0.C $\mathrm{O} ; 2-\mathrm{V}$
12. Yamada, S.; Nakawaga, Y.; Watabiki, O.; Suzuki, S.-i.; Ohashi, M. Chem. Lett. 1986, 361-364. doi:10.1246/cl.1986.361

13. Ohashi, M.; Kudo, H.; Yamada, S. J. Am. Chem. Soc. 1979, 101, 2201-2202. doi:10.1021/ja00502a045

14. Koshima, H.; Ding, K.; Chisaka, Y.; Matsuura, T.; Ohashi, Y.; Mukasa, M. J. Org. Chem. 1996, 61, 2352-2357. doi:10.1021/jo951642।

15. Fasani, E.; Peverali, D.; Albini, A. Tetrahedron Lett. 1994, 35, 9275-9278. doi:10.1016/0040-4039(94)88486-2

16. Mella, M.; Fasani, E.; Albini, A. J. Org. Chem. 1992, 57, 3051-3057. doi:10.1021/jo00037a020

17. Hasegawa, E.; Brumfield, M. A.; Mariano, P. S.; Yoon, U. C. J. Org. Chem. 1988, 53, 5435-5442. doi:10.1021/jo00258a007

18. Kyushin, S.; Masuda, Y.; Matsushita, M.; Nakadaira, Y.; Ohashi, M. Tetrahedron Lett. 1990, 31, 6395-6398. doi:10.1016/S0040-4039(00)97074-6

19. Fagnoni, M.; Mella, M.; Albini, A. Tetrahedron 1994, 50, 6401-6410. doi:10.1016/S0040-4020(01)80656-6

20. Mizuno, K.; Ikeda, M.; Otsuji, Y. Tetrahedron Lett. 1985, 26, 461-464. doi:10.1016/S0040-4039(00)61911-1

21. Mella, M.; d'Alessandro, N.; Freccero, M.; Albini, A. J. Chem. Soc., Perkin Trans. 2 1993, 515-519. doi:10.1039/P29930000515

22. Mella, M.; Fasani, E.; Albini, A. J. Org. Chem. 1992, 57, 6210-6216. doi:10.1021/jo00049a031

23. Bardi, L.; Fasani, E.; Albini, A. J. Chem. Soc., Perkin Trans. 1 1994, 545-549. doi:10.1039/P19940000545

24. Shukla, D.; Young, R. H.; Farid, S. J. Phys. Chem. A 2004, 108, 10386-10394. doi:10.1021/jp0466340

25. Mella, M.; Freccero, M.; Albini, A. J. Chem. Soc., Chem. Commun. 1995, 41-42. doi:10.1039/C39950000041

26. Schreiner, P. R.; Wittkopp, A.; Gunchenko, P. A.; Yaroshinsky, A. I.; Peleshanko, S. A.; Fokin, A. A. Chem.-Eur. J. 2001, 7, 2739-2744. doi:10.1002/1521-3765(20010702)7:13<2739::AID-CHEM2739>3.0.C O;2-R

27. Mella, M.; Freccero, M.; Albini, A. Tetrahedron 1996, 52, 5549-5562. doi:10.1016/0040-4020(96)00195-0

28. Fagnoni, M.; Mella, M.; Albini, A. J. Am. Chem. Soc. 1995, 117, 7877-7881. doi:10.1021/ja00135a004

29. Fagnoni, M.; Mella, M.; Albini, A. J. Org. Chem. 1998, 63, 4026-4033. doi:10.1021/jo980093r

30. Fagnoni, M.; Dondi, D.; Ravelli, D.; Albini, A. Chem. Rev. 2007, 107, 2725-2756. doi:10.1021/cr068352x

31. Ravelli, D.; Fagnoni, M.; Albini, A. Chem. Soc. Rev. 2013, 42, 97-113. doi:10.1039/C2CS35250H

32. Albini, A.; Fagnoni, M.; Mella, M. Pure Appl. Chem. 2000, 72, 1321-1326. doi:10.1351/pac200072071321

33. Wagner-Czauderna, E.; Kalinowski, M. K. Collect. Czech. Chem. Commun. 2000, 65, 1573-1579. doi:10.1135/cccc20001573

34. Pedersen, S. U.; Christensen, T. B.; Thomasen, T.; Daasbjerg, K. J. Electroanal. Chem. 1998, 454, 123-143. doi:10.1016/S0022-0728(98)00195-8

35. Shida, T. Electronic Absorption Spectra of Radical Ions. In Physical Sciences Data 34; Elsevier: Amsterdam, 1988.

36. Masahiro Irie, M.; Tomimoto, S.; Hayashi, K. J. Phys. Chem. 1972, 76, 1419-1424. doi:10.1021/j100654a008

37. Freccero, M.; Mella, M.; Albini, A. Tetrahedron 1994, 7, 2115-2130. doi:10.1016/S0040-4020(01)85074-2 
38. Kellett, M. A.; Whitten, D. G.; Gould, I. R.; Bergmark, W. R. J. Am. Chem. Soc. 1991, 113, 358-359. doi:10.1021/ja00001a052

39. $\Delta G$ is always negative in the processes considered; in particular, the electron transfer is expected to be exoergonic by ca. 63 and $12 \mathrm{kcal}$ $\mathrm{mol}^{-1}$ in the most and least favorable case, respectively.

40. Lund, T.; Christensen, R.; Wilbrandt, R. Org. Biomol. Chem. 2003, 1 , 1020-1025. doi:10.1039/B209594G

41. Tsukuda, T.; Kondow, T.; Dessent, C. E. H.; Bailey, C. G.; Johnson, M. A.; Hendricks, J. H.; Lyapustina, S. A.; Bowen, K. H. Chem. Phys. Lett. 1997, 269, 17-21. doi:10.1016/S0009-2614(97)00255-8

42. Del Sesto, R. E.; Arif, A. M.; Novoa, J. J.; Anusiewicz, I.; Skurski, P.; Simons, J.; Dunn, B. C.; Eyring, E. M.; Miller, J. S. J. Org. Chem. 2003, 68, 3367-3379. doi:10.1021/jo025833h

43. Gosztola, D.; Niemczyk, M. P.; Svec, W.; Lukas, A. S.; Wasielewski, M. R. J. Phys. Chem. A 2000, 104, 6545-6551. doi:10.1021/jp000706f

44. Webster, R. D.; Bond, A. M.; Coomber, D. C. J. Electroanal. Chem. 1998, 442, 217-227. doi:10.1016/S0022-0728(97)00465-8

45. Webster, R. D.; Bond, A. M.; Compton, R. G. J. Phys. Chem. 1996, 100, 10288-10297. doi:10.1021/jp9601173

46. Wayner, D. D. M.; McPhee, D. J.; Griller, D. J. Am. Chem. Soc. 1988, 110, 132-137. doi:10.1021/ja00209a021

47. Wayner, D. D. M.; Houman, A. Acta Chem. Scand. 1998, 52, 377-384. doi:10.3891/acta.chem.scand.52-0377

48. von Raumer, M.; Suppan, P.; Haselbach, E. Chem. Phys. Lett. 1996, 252, 263-266. doi:10.1016/0009-2614(96)00138-8

49. Lalevée, J.; Allonas, X.; Fouassier, J. P. J. Am. Chem. Soc. 2002, 124, 9613-9621. doi:10.1021/ja0204168

50. Markus von Raumer, M.; Suppan, P.; Haselbach, E. Helv. Chim. Acta 1997, 80, 719-724. doi:10.1002/hlca.19970800309

51. Inbar, S.; Linschitz, H.; Cohen, S. G. J. Am. Chem. Soc. 1981, 103, 1048-1054. doi:10.1021/ja00395a009

52. Bhattacharyya, K.; Das, P. K. J. Phys. Chem. 1986, 90, 3987-3993. doi:10.1021/j100408a032

53. Protti, S.; Fagnoni, M.; Monti, S.; Réhault, J.; Poizat, O.; Albini, A. RSC Adv. 2012, 2, 1897-1904. doi:10.1039/C2RA01054B

54. Jonsson, M.; Wayner, D. D. M.; Lusztyk, J. J. Phys. Chem. 1996, 100, 17539-17543. doi:10.1021/jp961286q

55. Lewis, F. D.; Zebrowski, B. E.; Correa, P. E. J. Am. Chem. Soc. 1984, 106, 187-193. doi:10.1021/ja00313a038

56. Lawton, E. A.; McRichtie, D. A. J. Org. Chem. 1959, 24, 26-28. doi:10.1021/jo01083a008

57. Çakmak, O.; Kahveci, I.; Demirtaş, I.; Hökelek, T.; Smith, K. Collect. Czech. Chem. Commun. 2000, 65, 1791-1804. doi:10.1135/cccc20001791

58. Yamasaki, N.; Inoue, Y.; Yokoyama, T.; Tai, A.; Ishida, A.; Takamuku, S. J. Am. Chem. Soc. 1991, 113, 1933-1941. doi:10.1021/ja00006a011

59. Leonard, N. J.; Paukstelis, J. V.; Brady, L. E. J. Org. Chem. 1964, 29, 3383-3386. doi:10.1021/jo01034a062

60. Hub, W.; Schneider, S.; Dorr, F.; Oxman, J. D.; Lewis, F. D. J. Am. Chem. Soc. 1984, 106, 701-708. doi:10.1021/ja00315a040

61. Pischel, U.; Zhang, X.; Hellrung, B.; Haselbach, E.; Muller, P.-M.; Nau, W. M. J. Am. Chem. Soc. 2000, 122, 2027-2034. doi:10.1021/ja992508b

62. Yoshida, J.-i.; Izawa, M. J. Am. Chem. Soc. 1997, 119, 9361-9365. doi:10.1021/ja970899t

63. Rehm, D.; Weller, A. Isr. J. Chem. 1970, 8, 259-271.

\section{License and Terms}

This is an Open Access article under the terms of the Creative Commons Attribution License

(http://creativecommons.org/licenses/by/2.0), which permits unrestricted use, distribution, and reproduction in any medium, provided the original work is properly cited.

The license is subject to the Beilstein Journal of Organic Chemistry terms and conditions:

(http://www.beilstein-journals.org/bjoc)

The definitive version of this article is the electronic one which can be found at: doi:10.3762/bjoc.9.91 